\title{
Predictions for Total Solar Eclipses of 2008, 2009 and 2010
}

\author{
Fred Espenak ${ }^{1}$ and Jay Anderson ${ }^{2}$ \\ ${ }^{1}$ NASA's Goddard Space Flight Center, Greenbelt, Maryland 20771, USA \\ email: espenak@gsfc.nasa.gov \\ ${ }^{2}$ University of Manitoba, Dept. of Environment and Geography, 496 Wallace Building, \\ Winnipeg, MB Canada R3T 2N2 \\ email: jander@cc.umanitoba.ca
}

\begin{abstract}
A brief overview of upcoming total solar eclipses in 2008-2010 is presented. Global maps illustrate the geographic region of visibility for each eclipse. In addition, preliminary weather prospects are discussed.
\end{abstract}

Keywords. eclipses, Sun: corona, Moon

\section{Introduction}

Total eclipses of the Sun offer astronomers and physicists the unique opportunity to conduct ground based investigations of the solar corona using state-of-the-art instrumentation and techniques at a fraction of the cost of dedicated satellite missions. However, total eclipses are relatively infrequent phenomena occurring once every year or two and typically last just two to four minutes. Therefore, eclipse experiments must be planned years in advance to maximize the data return during these brief opportunities.

Following the recent total solar eclipse of 2006 Mar 29, it is timely to look at prospects for the next three total solar eclipses in 2008, 2009 and 2010. These events are each separated by twelve lunations and take place during the middle of Northern Hemisphere summer.

\section{2008 Eclipse}

The total eclipse of 2008 occurs on Friday, August 1. The narrow corridor traversed by the Moon's umbral shadow extends from northern Canada to central Asia. A partial eclipse will be seen within the much broader path of the Moon's penumbral shadow, which includes northeastern North America, most of Europe and Asia (figure 1).

The path of totality begins in northern Canada in the province of Nunavut at 09:23 UT and quickly travels north across Devon Island, Ellesmere Island, northern Greenland and the Arctic Ocean. As the track turns to the south it passes between Spitzbergen and Franz Joseph Land before bisecting Russia's Novaya Zemlya. The northern Russian city of Nadym lies near the point of greatest eclipse which occurs

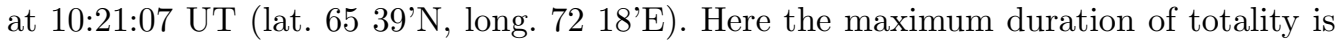
2 minutes 27 seconds with the Sun 33 above the horizon.

Continuing south, the track crosses central Siberia. With 2.7 million inhabitants, Novosibirsk is the largest Russian city in the path. Totality begins here at 10:44 UT and lasts 2 minutes 18 seconds. As the Moon's umbral shadow exits Russia, it briefly encompasses the intersection of four nations: Russian, Kazakhstan, China and Mongolia. The center of the track follows the China-Mongolia border for several hundred kilometers 


\title{
Figure 1
}

\section{Total Solar Eclipse of 2008 Aug 01}

\author{
Geocentric Conjunction $=09: 47: 21.6 \mathrm{UT}$ \\ $\mathrm{J} . \mathrm{D} .=2454679.907888$ \\ Greatest Eclipse $=10: 21: 07.0 \mathrm{UT}$ \\ $\mathrm{J} . \mathrm{D} .=2454679.931331$
}

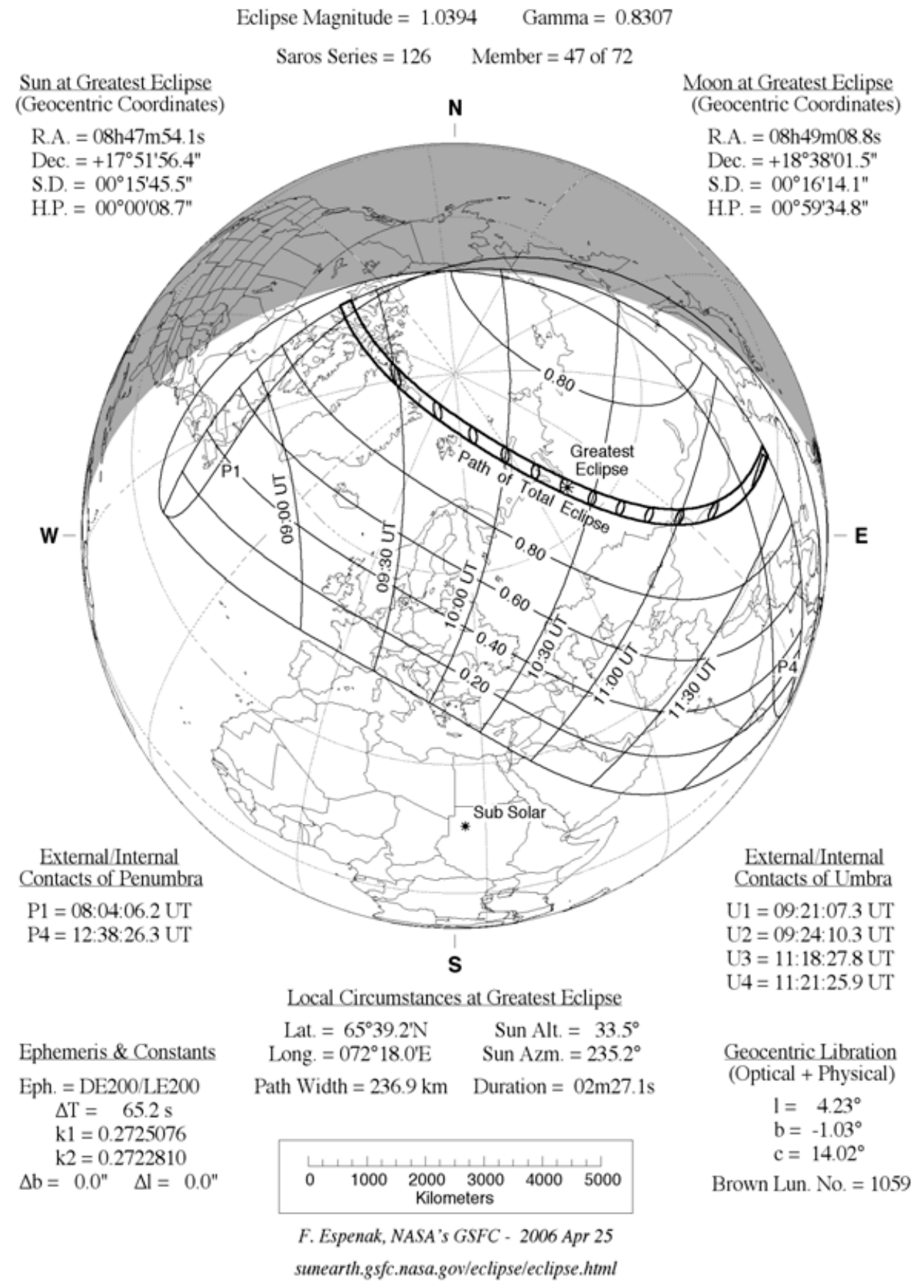




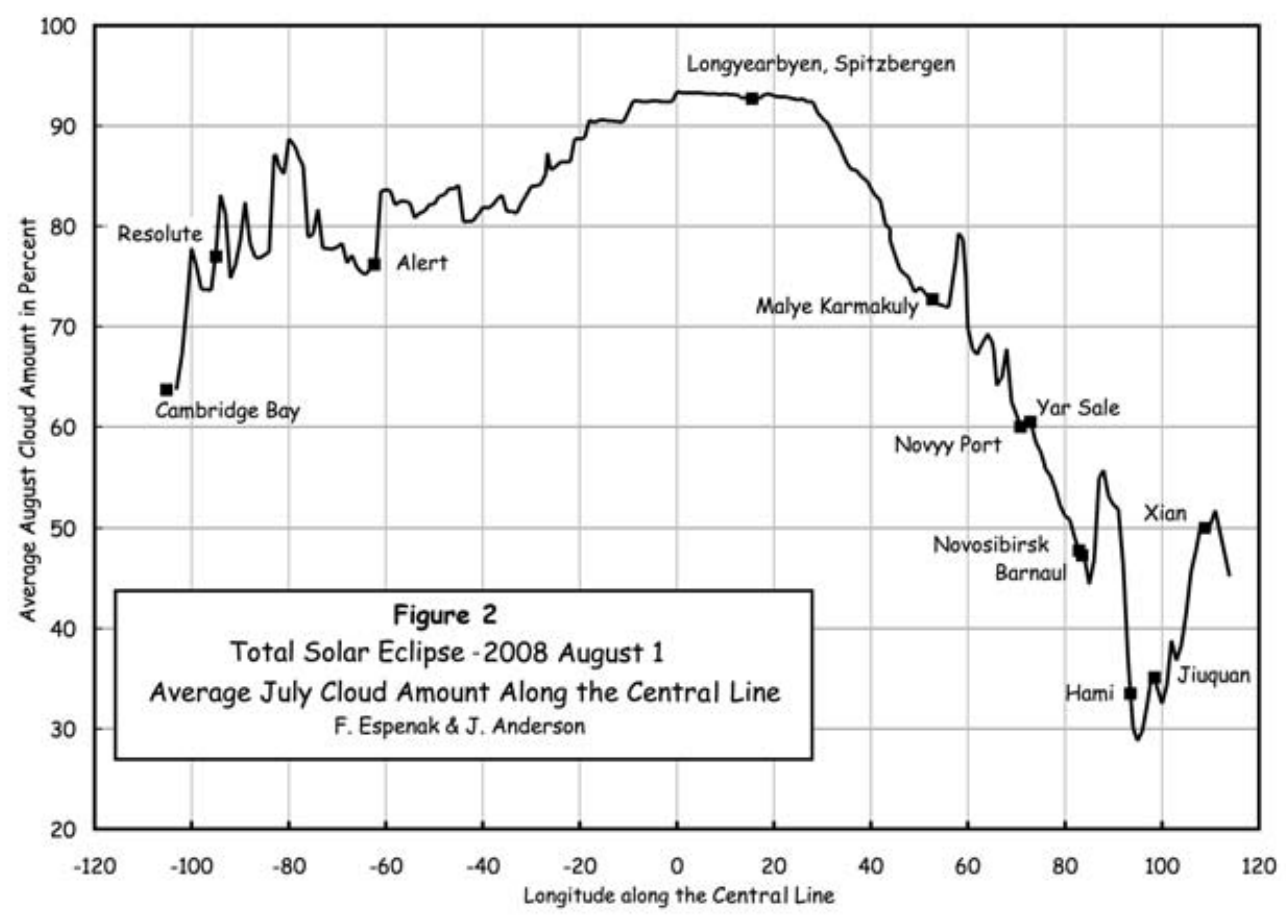

while the central duration and the Sun's altitude both decrease. Totality drops below two minutes with a Sun altitude of 18 at the central line east of Hami, China. The path passes north of Xian before ending at sunset near Zhengzhou (11:20 UT).

Mean cloudiness maps have been derived from nearly two decades of polar and geostationary satellite imagery from NOAA and the Satellite Active Archive. The maps were used to generate a graph of average cloud amount during August along the entire eclipse track (figure 2). Average cloudiness through Nunavut, Canada typically runs $70 \%$ to $80 \%$ while the Arctic portion of the path climbs over $90 \%$. The cloud prospects steadily improve as the path swings south through Asia. Russia's cloudiness values trend from $70 \%$ down to $50 \%$ (near Novosibirsk). The lowest average cloudiness of $30 \%$ occurs near Hami, China before climbing back up to $50 \%$ near the end of the path. These data identify northern China as the location with the highest probability of clear weather during the 2008 eclipse.

\section{2009 Eclipse}

The total eclipse of 2009 occurs on Wednesday, July 22. The path of the Moon's umbral shadow begins in south Asia and extends across the western Pacific Ocean. A partial eclipse will be seen from most of eastern Asia, Indonesia, and the Pacific Ocean (figure 3).

The path of totality begins at 00:53 UT in India's Gulf of Khambhat. It continues northeast through India and crosses parts of Nepal, Bangladesh, Bhutan and Myanmar. Entering China in the southern Himalayas, the shadow's trajectory sweeps east where it encounters Shanghai (population 18.7 million) at 01:37 UT. The duration of totality in Shanghai is 5 minutes, but the central line, 65 kilometers to the south, has a longer duration approaching nearly 6 minutes. After leaving main-land China, the path crosses 
Figure 3

\section{Total Solar Eclipse of 2009 Jul 22}

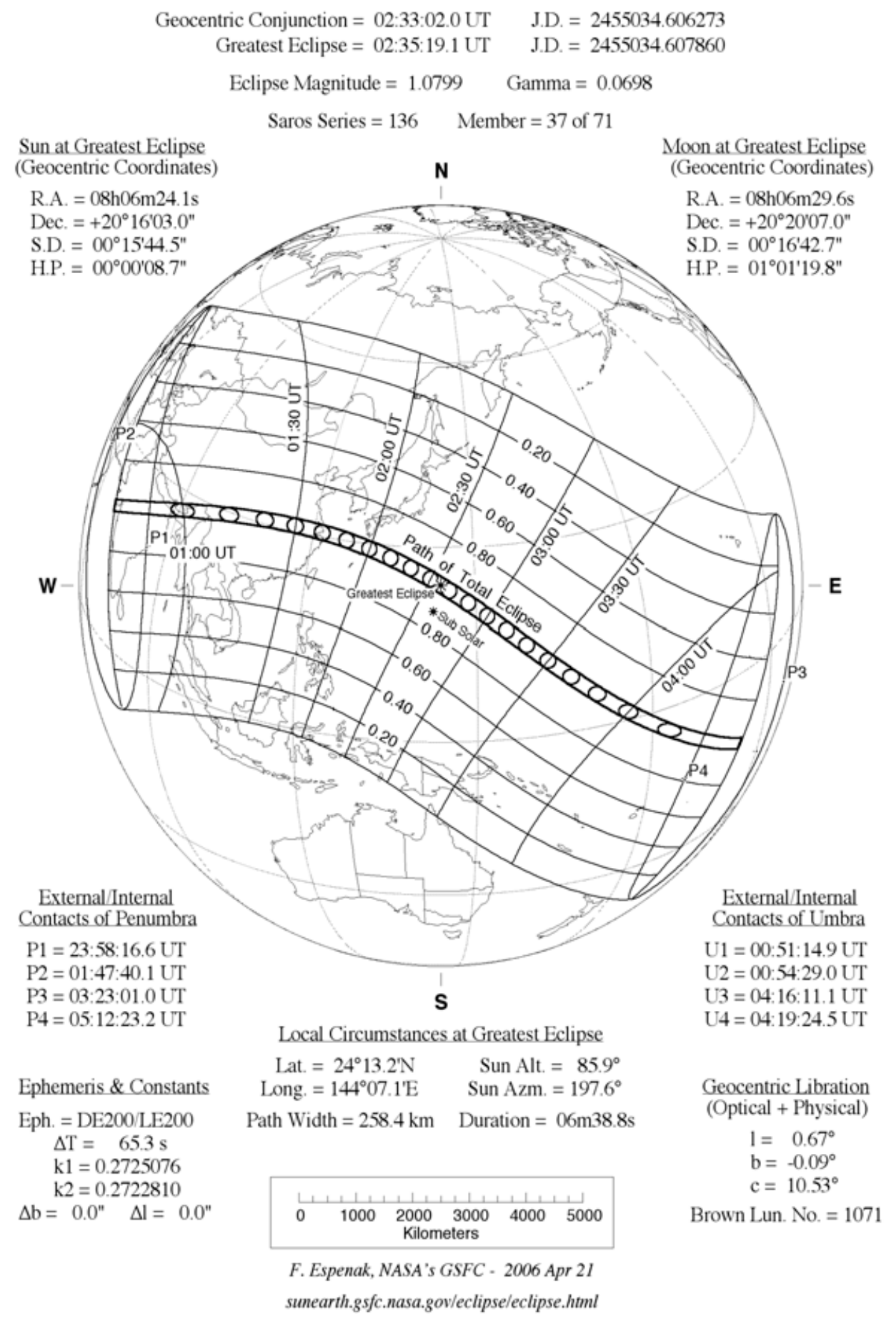




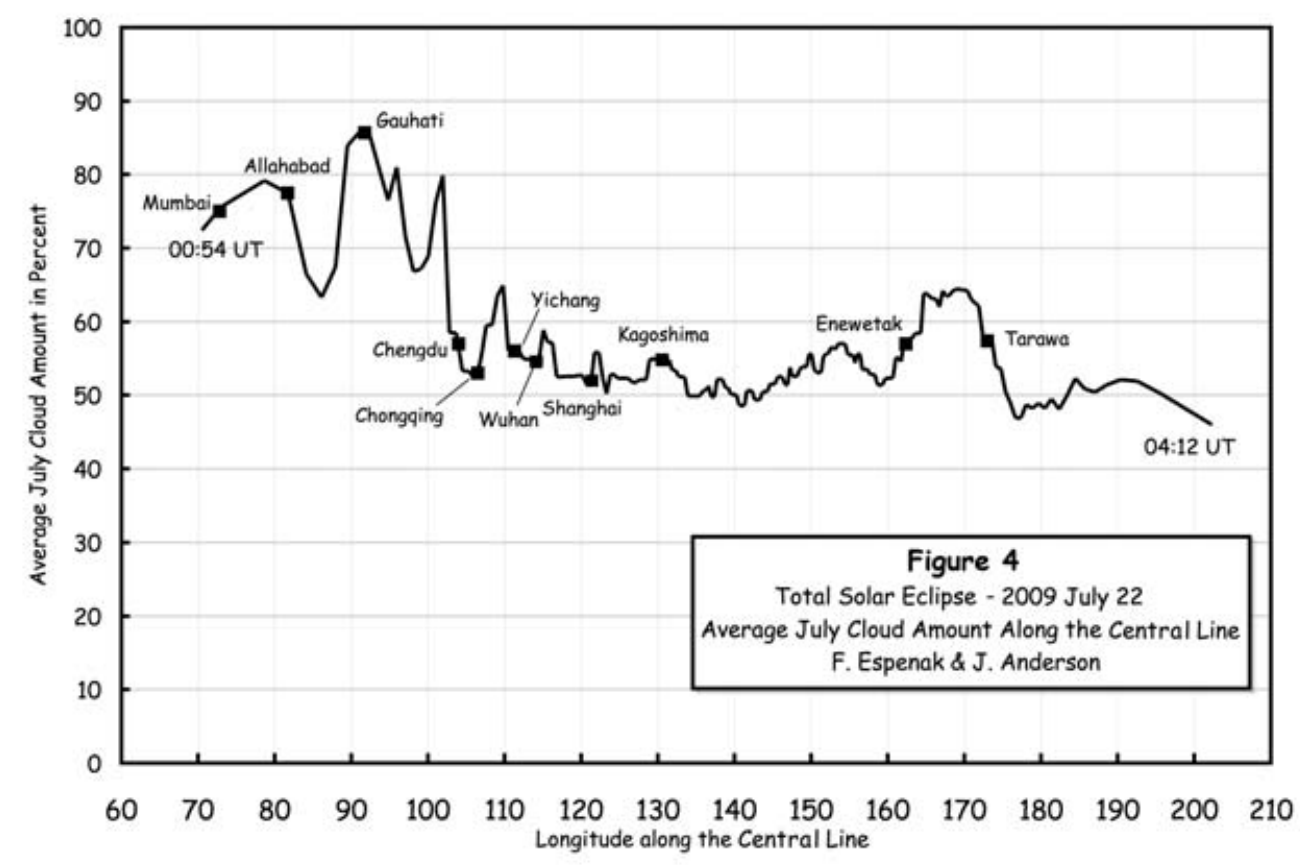

Japan's Ryukyu Islands and swings southeast. The point of greatest eclipse is reached at 02:35:19 UT (lat. 24 13'N, long. 144 07'E) in the Pacific Ocean. The maximum duration of totality here is 6 minutes 39 seconds with the Sun at an altitude of 86 .

Continuing across the South Pacific, the umbra's path takes it through the Marshall and Gilbert Islands from 03:30 UT to 04:00 UT. The eclipse track ends in the South Pacific at 04:18 UT.

Occurring as it does in the middle of South Asia's summer monsoon season, weather prospects for eclipse viewing in India are decidedly unfavorable with average cloudiness values in the $70 \%$ to $80 \%$ range (figure 4). After crossing the Himalayas, the cloud amount drops to $50 \%$ to $60 \%$ throughout China. Unfortunately, there is little statistical improvement in average cloudiness across the South Pacific. Nevertheless, the long duration of totality approaching 6 minutes in China clearly identifies that country as a prime destination for eclipse expeditions.

\section{2010 Eclipse}

The final total eclipse of the decade occurs on Wednesday, 2010 July 11. The Moon's umbral shadow traverses the South Pacific Ocean while a partial eclipse will be seen from most of the Pacific and southern South America (figure 5).

The lunar shadow's path begins at 18:17 UT about 1500 kilometers northeast of New Zealand. A few minutes later, the umbra passes through the Southern Cook Islands. By 18:28 UT, the shadow passes within 50 kilometers of Tahiti and crosses a number of the small atolls of Tuamotu. The central duration here is already four minutes and increasing. Unfortunately the point of greatest eclipse (19:33:32 UT) occurs in the mid-Pacific far from any land (lat. 19 45'S, long. $12152^{\prime} \mathrm{W}$ ). The maximum duration of totality is 5 minutes 20 seconds with the Sun's altitude at 47. 
Figure 5

\section{Total Solar Eclipse of 2010 Jul 11}

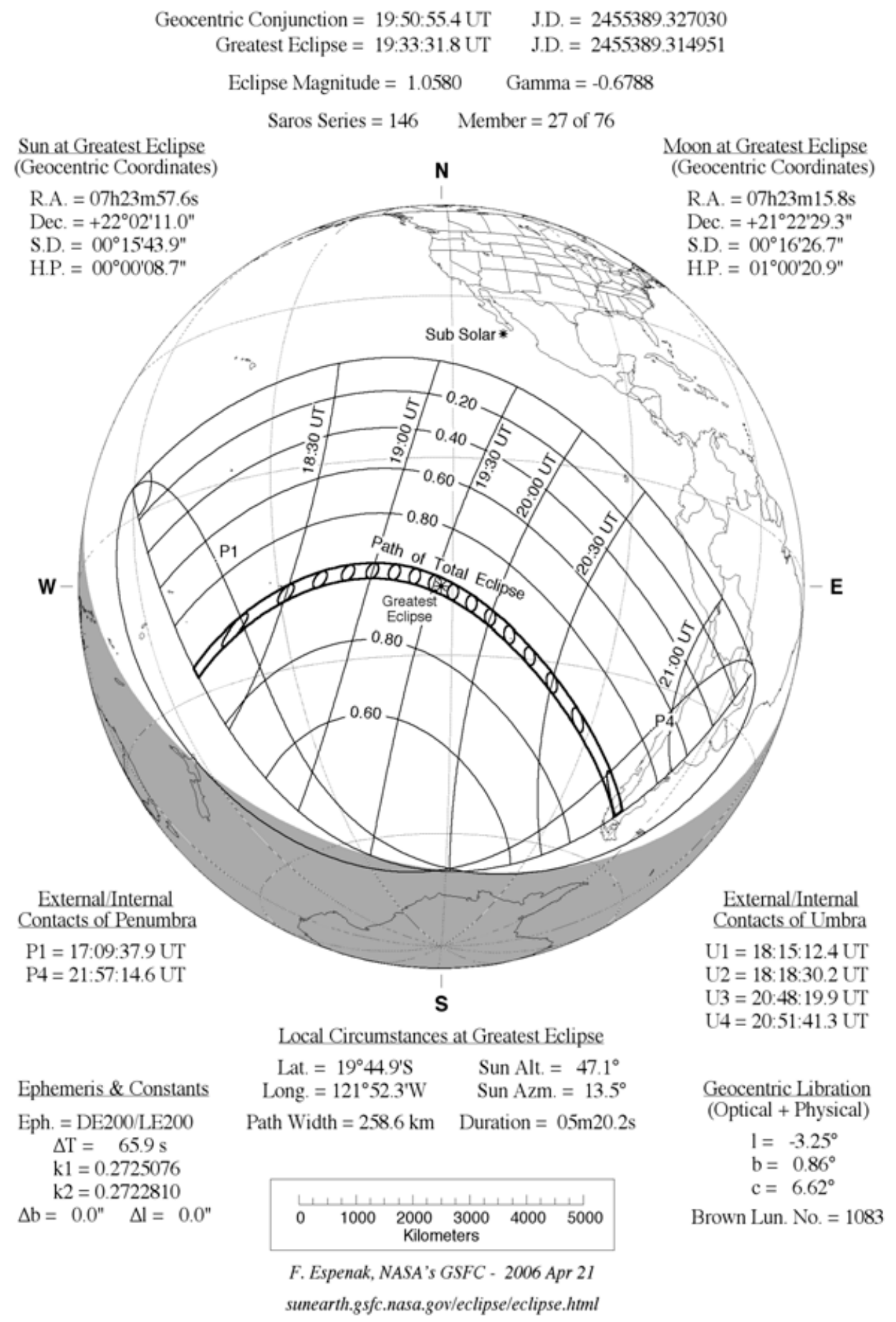




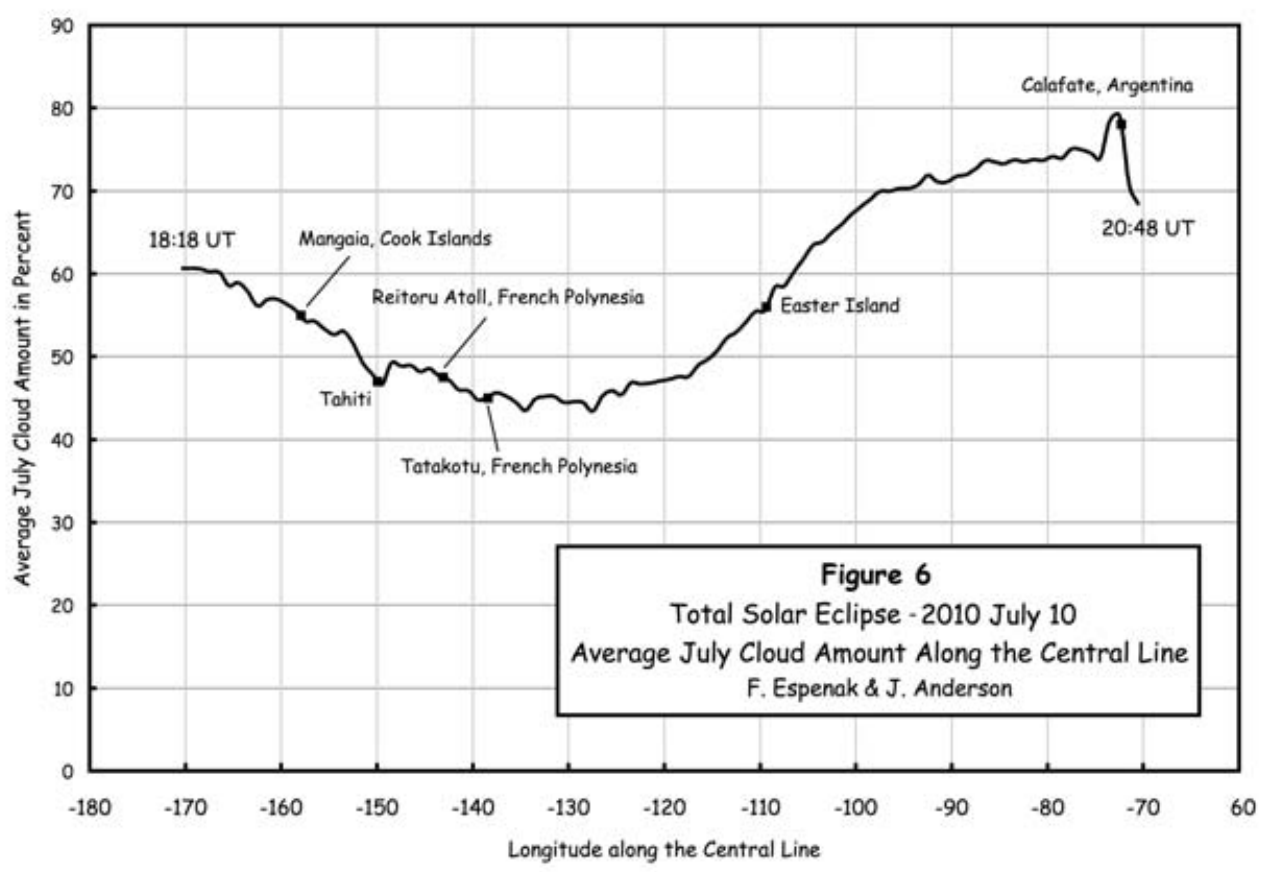

The next landfall of any consequence occurs at 20:11 UT when the path crosses Easter Island. Totality on the isolated isle lasts 4 minutes 44 seconds with the Sun at 39 . The eclipse track ends at sunset in southern Chile and Argentina with a 2 minute 45 second total eclipse at 20:50 UT.

A graph of average cloud amount in July along the eclipse path reveals a minimum of $45 \%$ in the region east of Tahiti (figure 6). Easter Island has an average cloudiness of $56 \%$. Although Chile and Argentina offer terra firma for eclipse investigations, it is a mountainous area in mid winter. Consequently, average cloud values are around $75 \%$. In summary, Easter Island appears to have the best prospects for land-based observations during the 2010 total solar eclipse.

\section{Conclusions}

The total eclipses of 2008, 2009 and 2010 present three excellent opportunities to investigate the nature and physics of the solar corona using ground based instrumentation. One or more land based locations with reasonable weather prospects are available for each eclipse.

These eclipse predictions were generated on an Apple G4 Macintosh computer using algorithms developed from the Explanatory Supplement (1974) with additional algorithms from Meeus, Grosjean, and Vanderleen (1966). The solar and lunar ephemerides were generated from the JPL DE200/LE200.

\section{References}

Espenak, F. 1987, Fifty Year Canon of Solar Eclipses: 1986-2035, NASA Ref. Pub. 1178, Goddard Space Flight Center, Greenbelt, Maryland

Her Majesty's Nautical Almanac Office 1974, Explanatory Supplement to the Astronomical Ephemeris and the American Ephemeris and Nautical Almanac, London 
Meeus, J., C. Grosjean, and W. Vanderleen 1966, Canon of Solar Eclipses, Pergamon Press, New York

NOAA's Satellite Active Archive 2006, http://directory.eoportal.org/ info_NOAAsSatelliteActiveArchiveSAA.html

Warren, S.G., Hahn, C.J. London, J. Chervin, R.M., and Jenne, R.L. 1986, Global Distribution of Total Cloud Cover and Cloud Type Amounts Over Land NCAR Tech. Note NCAR/TN273+STR and DOE Tech. Rept. No. DOE/ER/60085-H1, U.S. Department of Energy, Carbon Dioxide Research Division, Washington, DC, (NTIS number DE87-006903) 